\title{
Bettina Burger
}

\section{Xu Daozhi, Indigenous Cultural Capital: Postcolonial Narratives in Australian Children's Literature}

\author{
Oxford: Peter Lang 2018. 231 pp. ISBN: 978-1-78707-077-6. EUR 74,90
}

Australian children's literature, written by both Aboriginal and non-Aboriginal writers, ${ }^{1}$ has long been heavily invested in depictions of Aboriginality, be it in the form of Aboriginal protagonists, Aboriginal themes, or Aboriginal stories and epistemologies as a core inspiration. Xu Daozhi's 'Indigenous Cultural Capital. Postcolonial Narratives in Australian Children's Literature' analyses "books with Aboriginal themes" (p. 12n3), which is Daozhi's term for texts with Aboriginal content "across a wide range of genres including Dreaming stories, novels, autobiographies, picture books, textbooks and other reading material" (p. 5) regardless of whether their authors are Aboriginal or non-Aboriginal. Xu Daozhi looks at these texts through the lens of Pierre Bourdieu's concept of 'cultural capital'.2 She mainly relies on Bourdieu's three key elements of 'cultural capital', namely "the embodied or internalised state", "the objectified form of culture or cultural goods", and "the institutionalised form" (p. 14) to guide her reading of Australian children's literature. Her work focuses on the use of Aboriginal culture and its consequences for the reception and impact of the books in question, but also draws on concepts of 'gift-giving,' both from a sociological and an Indigenous perspective.

'Indigenous Cultural Capital' is divided into three parts, the first of which covers the actual treatment of Aboriginal cultural material in children's books while part II deals with the way in which children's books with Aboriginal themes receive institutional endorsements through reviews, prizes, paratextual spaces and use in educational settings. Part III examines ethical questions with regards to the representation of Aboriginality by analysing both Aboriginal and non-Aboriginal authors' ethical responsibility to traditional Aboriginal knowledge holders. The book's introduction provides a very clear and concise overview of this structure and states the aim of Xu Daozhi's argument: That Aboriginal-themed children's books can contribute to the empowerment of Aboriginal voices as well as provide cultural enrichment to young readers.

1 My usage of the terms 'Aboriginal' and 'Indigenous' mirrors the one employed by $\mathrm{Xu}$ Daozhi. Xu Daozhi uses the terms interchangeably due to their perceived fluidity in literature, but generally reserves 'Indigenous' for "overarching theoretical claim[s]" (p. 4n2).As with Xu Daozhi, 'Aboriginal' here also includes Torres Strait Islanders.

2 Bourdieu is a twentieth-century French sociologist and philosopher whose "theory has been criticised for economic reductionism" (p. 14) but whose terminology continues to be cited and employed to this day - Google Scholar provides an approximate estimation of his ongoing popularity as the search term "Pierre Bourdieu cultural capital" yields 7.190 entries for 2020 alone. 
Additionally, $\mathrm{Xu}$ Daozhi uses her introduction to give a short chronological overview of Australian children's literature and its connection to Aboriginality, starting with Charlotte Barton's 'A Mother's Offering to Her Children' (1841) and its stereotypical portrayal of Aboriginal people, proceeding to collections of Aboriginal myths and legends, the most famous of which is arguably Kate Langloh Parker's 'Australian Legendary Tales' (1896), and covering previously highly acclaimed and now controversial authors such as Patricia Wrightson. Wrightson, though well-intentioned, appropriated Aboriginal beliefs for her children's fantasy novels and has been widely criticised. Daozhi's "chronological sketch" (p. 5) culminates in the rise of Aboriginal children's writers such as Wilf Reeves and Olga Miller, Oodgeroo Noonuccal, and Dick Roughsey. She then goes on to locate her work within postcolonial studies as a wider context, drawing on renowned postcolonial scholars such as Bill Ashcroft, Helen Tiffin, Graham Huggan, and Mary Louis Pratt. Among the selected scholars is also Clare Bradford, who is particularly relevant for Daozhi's research, as she also focuses on Australian Children's Literature with a pronounced interest in Aboriginal issues. While Daozhi's situating of her monograph within postcolonial studies is convincing, a brief discussion of other (postcolonial) scholars of children's literature might have been interesting. Perhaps an engagement with Perry Nodelman's not entirely uncontroversial “The Other: Orientalism, Colonialism, and Children's literature," which suggests that children's literature itself may be implicated in the imperialist oppression of childhood, or Roderick McGillis' essay collection 'Voices of the Other: Children's Literature and the Postcolonial Context', which covers a wide range of both colonial and postcolonial children's literature, could have added some additional depth to Xu Daozhi's argument. Chronology and critical context are followed by a concise and helpful explanation of Bourdieu's concept of cultural capital as well as Xu Daozhi's use of the term in the context of (Aboriginal) children's literature. Xu Daozhi ends her introduction with a number of guiding questions, and explanation of her structure and her main thesis.

Chapter 1, 'Decolonised Landscape: Aboriginal Connection to Country' analyses the depiction of an "Aboriginal perception of the human-land relationship" (p. 44) in three main texts - two novels by white writers, Kate Constable's 'Crow Country' and James Moloney's 'Gracey', as well as the collaborative picture book 'Jimmy and Pat Meet the Queen' by white writer Pat Lowe and Aboriginal artist Jimmy Pike. The chapter starts with an explanation of the Aboriginal concept of 'country' as well as a brief introduction to the colonialist framing of Australia as an empty space or 'terra nullius', which in turn provide a suitable context for the following discussion of $\mathrm{Xu}$ Daozhi's primary literature.

Chapter 2 is mainly concerned with life writing texts that address the lives of children, who were taken away from their Aboriginal families and are thus considered part of the Stolen Generations. While interesting on its own, the chapter seems to be the weakest in Xu Daozhi's book, as its connection to children's literature and the use of Indigenous cultural capital in books marketed towards children remains relatively flimsy. $\mathrm{Xu}$ Daozhi does make reference to “O'Donoghue's autobiography where the top right corner of nearly every page with text provides for young readers the explanations of specific terms" (p. 89) in detail and to a graphic novel more specifically geared towards children and young adults in passing. However, there is 
no discussion of how autobiographies may address child audiences in particular to pass on the Indigenous cultural capital produced through such memoirs. While $\mathrm{Xu}$ Daozhi acknowledges in her introduction that her corpus includes books "written for or about children" (p.5, my emphasis), the chapter still stands out from the others, which are all addressing books specifically written for children, albeit sometimes in connection to their reception from adults.

Chapter 3 and 4 go into more detail as to how Indigenous cultural capital is produced and then disseminated. Chapter 3 contains a fascinating study on the reception of children's literature with Aboriginal themes through three different approaches: Xu Daozhi focuses mostly on the third aspect of cultural capital identified by Bourdieu, namely its 'institutionalised form' and discusses how Aboriginality-themed children's literature can gain literary legitimation through reviews, literary prizes, and paratextual endorsements. To this end, $\mathrm{Xu}$ Daozhi looks at various historical developments; for example, the reviewing history of 'The Legends of Moonie Jarl', the first children's book by Aboriginal Australian authors, serves to show how attitudes towards Aboriginal people have changed and Indigenous cultural capital has been accrued over the years. Chapter 4 takes a similarly historical approach by looking at the presence of Aboriginal material in schools. Xu Daozhi discusses both the history of Australian curricula, which went from an almost complete absence of Aboriginal material in education to Aboriginality as one of several cross-curricular subjects, as well as the changes in a variety of school readers. She charts the development of reader content from mainly British material to Australian, but racially highly problematic texts, and finally towards "the recently published series of 'Indij Readers'" (p. 164), which specifically serves to distribute Aboriginal writing to both Aboriginal and non-Aboriginal schoolchildren.

In Chapter 5, Xu Daozhi addresses a highly controversial topic - the representation of Aboriginal themes and characters by various authors of both Aboriginal and non-Aboriginal heritage. Her negative examples include the well-known writer Patricia Wrightson and the controversies surrounding her fantasy writing as well as the conflict surrounding the realist young adult novel 'Deadly, Unna?' by white author Phillip Gwynne, which revolves around the shooting of two Aboriginal teenagers. However, she also highlights the positive example of white author Kate Constable employing a Dreaming figure (Waa the Crow) as a narrative device while not only acknowledging the traditional knowledge holders but also cooperating with them to ensure a final product that is accepted by the Aboriginal group from which the Dreaming figure originates. Xu Daozhi's approach is particularly interesting because she acknowledges the dangers and pitfalls as well as the ethical dilemma that comes with representing Aboriginal stories while not being Aboriginal but does not endorse a blanket ban. Instead, Xu Daozhi turns to the practice of gift-giving. Crucially, she does not frame Aboriginal stories as a gift to be appropriated by white writers, but as a potential of creative source material that Aboriginal people may choose to share. Such a gift, of course, requires not only communication with the Aboriginal group involved but also reciprocal action, that may manifest, for example, in working towards improving the living conditions of contemporary Aboriginal people. 
Xu Daozhi's 'Indigenous Cultural Capital' is an in-depth study on a specific subsection of Australian children's literature, namely those texts that revolve around Aboriginal themes. As such, it is a valuable read not only for scholars of Australian literature but also for a wider audience of children's literature specialists, particularly those with an interest in postcolonial matters. Concisely, Xu Daozhi delineates how children's literature can produce and distribute Indigenous cultural capital, gain institutional legitimacy, and acknowledge its ethical responsibilities. 